\title{
Acanthamoeba castellanii of the T4 genotype is a potential environmental host for Enterobacter aerogenes and Aeromonas hydrophila
}

\author{
Farzana Abubakar Yousuf, Ruqaiyyah Siddiqui and Naveed Ahmed Khan*
}

\begin{abstract}
Background: Acanthamoeba can interact with a wide range of microorganisms such as viruses, algae, yeasts, protists and bacteria including Legionella pneumophila, Pseudomonas aeruginosa, Vibrio cholerae, Helicobacter pylori, Listeria monocytogenes, Mycobacterium spp., and Escherichia coli. In this capacity, Acanthamoeba has been suggested as a vector in the transmission of bacterial pathogens to the susceptible hosts.
\end{abstract}

Methods: Here, we used a keratitis isolate of A. castellanii of the T4 genotype and studied its interactions with two bacterial genera which have not been tested before, Enterobacter aerogenes, and Aeromonas hydrophila, as well as E. coli. Assays were performed to determine bacterial association with and invasion of A. castellanii. Additionally, bacterial survival intracellular of $A$. castellanii trophozoites as well as cysts was determined.

Results: All three bacterial isolates tested, associated, invaded, and survived inside A. castellanii trophozoites as well as A. castellanii cysts. However, E. aerogenes and E. coli exhibited significantly reduced association with and invasion of $A$. castellanii as compared with $A$. hydrophila ( $P<0.01$ using paired T-test, one tail distribution). In the long term survival assays, all three bacterial isolates tested remained viable inside $A$. castellanii trophozoites, while amoeba remained intact; however $A$. hydrophila exhibited higher survival inside amoebae (14.54 \pm 3.3 bacteria:amoeba ratio) compared with E. aerogenes (3.96 \pm 0.7 bacteria:amoeba ratio) and E. coli (5.85 \pm 1.1 bacteria:amoeba ratio).

A. hydrophila, E. coli, and E. aerogenes remained viable during the encystment process and exhibited higher levels of recovery from mature cysts (14.13 \pm 0.89 A. hydrophila:amoeba ratio, $10.13 \pm 1.17$ E. aerogenes:amoeba ratio, and $11.95 \pm 0.7$ E. coli:amoeba ratio).

Conclusions: A. hydrophila and E. aerogenes also joined the ranks of other bacteria that could benefit from A. castellanii. Because cysts can be airborne, these findings suggest that Acanthamoeba is a potential vector in the transmission of A. hydrophila and E. aerogenes to susceptible hosts.

Keywords: Acanthamoeba, Interactions, Encystment, Vector, Pathogens

\section{Background}

Acanthamoeba spp. were discovered in a culture of Cryptococcus pararoseus (fungus) by Castellani in 1930 [1-3]. Being free-living protists, Acanthamoeba spp. have the capability to endure harsh environments. There are two stages in the life cycle of Acanthamoeba i.e., a vegetative trophozoite stage and a resistant cyst stage. Bacteria, algae, yeasts or small organic particles are the source of nourishment for Acanthamoeba

\footnotetext{
* Correspondence: Naveed5438@gmail.com

Department of Biological and Biomedical Sciences, Aga Khan University, Karachi, Pakistan
}

during the trophozoite stage, while harsh environmental conditions (i.e., lack of food, increased osmolarity or hypo-osmolarity, extremes in temperatures and $\mathrm{pH}$ ) promote trophozoite conversion into the cyst stage. A number of studies have documented Acanthamoeba spp. as a reservoir for the survival of pathogenic bacteria in the environment [4], and suggested their potential role in the transmission of pathogenic microbes to the susceptible population, particularly in a clinical setting.

Enterobacter aerogenes (formerly known as Klebsiella aerogenes), a Gram negative bacterium belonging to 
the family of Enterobacteriaceae, is often associated with nosocomial infections [5]. The colonization of $E$. aerogenes most commonly occurs amongst intensive care unit (ICU) patients, usually in the respiratory, urinary, and gastrointestinal tracts and less frequently in skin and surgical wounds [6-10]. Another class of bacteria, i.e., Aeromonas hydrophila are Gramnegative enteropathogens that belong to the family Vibrionaceae. They are found in fresh water habitats throughout the world and infect cultured and feral fishes [11]. A number of epidemiological studies have demonstrated the presence of A. hydrophila in stools of young children with diarrhea. It has also been found to be associated with infections, such as endocarditis, gastroenteritis, hemolytic-uremic syndrome, meningitis, pneumonia, septicemia, urinary tract infections, wound infections, etc. [12]. In this study, we determined $A$. castellanii interactions with $E$. aerogenes and A. hydrophila.

\section{Methods}

\section{Culture of acanthamoeba}

All chemicals were purchased from Sigma Laboratories (St. Louis, USA) and Oxoid (Hampshire, England) unless otherwise stated. A clinical isolate of $A$. castellanii belonging to the $\mathrm{T} 4$ genotype, originally isolated from a keratitis patient (American Type Culture Collection, ATCC 50492) was used in the present study. A. castellanii was cultured in PYG medium containing $[0.75 \%(\mathrm{w} / \mathrm{v})$ proteose peptone, $0.75 \%(\mathrm{w} / \mathrm{v})$ yeast extract and $1.5 \%(\mathrm{w} / \mathrm{v})$ glucose $)]$. The amoebae were grown in tissue culture flasks at $30^{\circ} \mathrm{C}$ without shaking [13].

\section{Bacterial cultures}

E. aerogenes (formerly known as Klebsiella aerogenes) is a clinical isolate available in the university microbial collection. A clinical isolate of A. hydrophila (diarrheal patient and kindly provided by Dr. Anita Zaidi, Aga Khan University Hospital) was used in the present study. In addition, Escherichia coli K1 strain E44, a spontaneous rifampin-resistant mutant of a CSF isolate of K1-encapsulated E. coli RS218 was used (O18:K1: H7) $[14,15]$. Bacteria were cultured in Luria Bertani (LB) overnight at $37^{\circ} \mathrm{C}$ without shaking prior to experimentation.

\section{Antibiotic sensitivity assays}

For antibiotic susceptibility testing of E. aerogenes and A. hydrophila, the disk diffusion method was used according to Kirby-Bauer [16]. Tests were performed on Muller-Hinton agar and inhibition zone diameters were interpreted according to antimicrobial susceptibility CSLI guidelines [17].

\section{Association assays}

A. castellanii were maintained in the trophozoite stage in tissue culture flasks in PYG medium. Upon confluency, the unbound amoebae were aspirated and growing trophozoites were washed once with phosphate buffered saline (PBS) $\mathrm{pH}$ 7.4. The growth medium, PYG $(5 \mathrm{~mL})$ was added to the flask and trophozoites were chilled on ice for $20 \mathrm{~min}$, pelleted by centrifugation at $900 \times g$ for $5 \mathrm{~min}$. The cell pellet was dispersed in $1 \mathrm{~mL}$ of PBS and the number of amoebae were counted using a haemocytometer $\left(10^{6}\right)$. For bacterial cultures, the optical density was adjusted to 0.22 at $595 \mathrm{~nm}$ [equivalent to approximately $10^{8}$ colony forming units (c.f.u.) per $\mathrm{mL}$ ]. Bacteria $\left(10^{7}\right.$ c.f.u. $)$ were incubated with $A$. castellanii $\left(10^{6}\right.$ cells) at $30^{\circ} \mathrm{C}$ for $1 \mathrm{~h}$. After the incubation, co-cultures of amoebae plus bacteria were transferred to a $1.5 \mathrm{~mL}$ eppendorf tube and centrifuged at $2000 \times g$ for $5 \mathrm{~min}$. Next, the supernatant was aspirated and the pellet was resuspended in $0.5 \mathrm{~mL}$ of PBS and vortexed by a brief pulse. This process was repeated three times to remove nonassociated bacteria. At the final wash, the discarded supernatant was also plated onto nutrient agar plates to determine bacterial presence. Finally, amoebae were counted using a haemocytometer. The amoebae were lysed by adding sodium dodecyl sulfate (SDS; 0.5\% final concentration) and kept at room temperature for $10 \mathrm{~min}$. The lysates containing bacteria were plated onto nutrient agar plates and colonies enumerated the next day [18]. The percentage of bacterial association was calculated as follows: recovered bacterial c.f.u. / total bacterial c.f.u. $\times$ $100=\%$ bacterial c.f.u. associated with $A$. castellanii. In addition, the ratio of bacteria to amoebae was calculated as follows: recovered bacterial c.f.u. / number of $A$. castellanii $=$ bacterial c.f.u.:A. castellanii ratio.

\section{Invasion assays}

The ability of bacteria to invade or be taken up by $A$. castellanii was observed by performing invasion assays. Briefly, the amoebae were grown to confluency in a trophozoite stage in tissue culture flasks followed by the addition of bacteria as described for association assays. A. castellanii were incubated for $1 \mathrm{~h}$ and washed three times with PBS. The extracellular bacteria were killed by adding gentamicin $(100 \mu \mathrm{g}$ per $\mathrm{mL})$ and incubated for $45 \mathrm{~min}$ at $30^{\circ} \mathrm{C}$. After incubation in gentamicin, amoebae were washed three times in $500 \mu \mathrm{L}$ aliquots of PBS. At the final wash, the PBS was also plated onto nutrient agar plates to ensure any remaining extracellular bacteria had been killed. The washed amoebae were then resuspended in $500 \mu \mathrm{L}$ of fresh PBS and enumerated using a haemocytometer. Finally, amoebae were lysed 
using $0.5 \%$ SDS together with vortexing. Aliquots of the lysate were plated on nutrient agar plates to determine the bacterial counts. The susceptibility of bacteria to gentamicin was tested independently by incubating cultures of bacteria grown overnight with $100 \mu \mathrm{g}$ per $\mathrm{mL}$ as indicated above. The percentage of bacterial invasion/uptake was calculated as follows: recovered bacterial c.f.u. / total bacterial c.f.u. $\times 100=\%$ intracellular bacterial c.f. u.. In addition, the ratio of bacteria to amoebae was calculated as follows: recovered bacterial c.f.u./ number of $A$. castellanii $=$ bacterial c.f.u.:A. castellanii ratio.

\section{Intracellular survival assays}

The number of intracellular bacteria in A. castellanii was assessed by intracellular survival assays. Briefly, amoebae were incubated with bacteria, followed by the addition of gentamicin (100 $\mu \mathrm{g}$ per $\mathrm{mL})$ for $45 \mathrm{~min}$ as for invasion assays. After this incubation, A. castellanii were washed three times with $\mathrm{PBS}$ and subsequently incubated in $0.5 \mathrm{~mL}$ of PBS for $24 \mathrm{~h}$ at $30^{\circ} \mathrm{C}$. Finally, amoebae and bacterial c.f.u. were counted as described above and bacteria that had survived intracellularly were calculated as follows: recovered bacterial c.f.u. / total bacterial c.f.u. $\times 100=\%$ intracellular bacterial c.f.u. after $24 \mathrm{~h}$ in PBS. In addition, the ratio of bacteria to amoebae was calculated as follows: recovered bacterial c.f.u. / number of $A$. castellanii $=$ bacterial c.f.u.:A. castellanii ratio.

\section{Intracellular cyst survival assays}

Encystment assays were performed to evaluate the ability of bacteria to survive inside A castellanii cysts. In brief, following invasion assays, the mixtures were transferred onto non-nutrient agar plates without any bacterial lawn [prepared using 3\% (w/v) purified agar]. The plates were incubated at room temperature for up to 10 days. This allowed a complete encystment of $A$. castellanii trophozoites into the cyst form, as observed visually under a phase-contrast microscope. Cysts were then gently scraped-off the agar surface using a cell scraper by adding $5 \mathrm{~mL}$ of sterile deionized water and collected by centrifugation at $900 \times g$ for $10 \mathrm{~min}$ and resuspended in $0.5 \mathrm{~mL}$ of sterile deionized water and counted using a haemocytometer. The cysts were treated with SDS ( $0.5 \%$ final concentration) and the associated numbers of bacteria were enumerated by plating onto nutrient agar plates. The bacterial counts were calculated as follows: recovered bacterial c.f.u./ total bacterial c.f.u. $\times 100=\%$ bacterial c.f.u.. The ratio of bacteria to amoebae was calculated as follows: recovered bacterial c.f.u. / number of $A$. castellanii cysts = bacterial c.f.u.: A. castellanii cysts ratio. For controls, A. castellanii cysts were prepared in the absence of bacteria.

\section{Results}

Antibiotic susceptibility testing revealed that both $E$. aerogenes and A. hydrophila were sensitive to amoxicillin/ clavulanic acid, amikicin, aztreonam, imipenem, iperacillin,/ tazobactam, gentamicin, ceftriaxon, cefuroxime, ofloxacin, sulphamethoxazole/trimethoprim, cefixime, chloramphenicol but resistant to ampicillin.

\section{A. hydrophila displayed higher association with and invasion/uptake by $A$. castellanii as compared to $E$. coli and $E$. aerogenes}

Association assays were performed by incubating $E$. aerogenes, E. coli, and A. hydrophila with $A$. castellanii. The non-associated bacteria were removed by washing amoebae in PBS for 3 times. The supernatant of the final wash was plated on nutrient agar plates but did not reveal any bacterial presence. Amoebae were then lysed using $0.5 \%$ SDS and lysates plated on nutrient agar plates. The findings revealed that $E$. aerogenes and $E$. coli demonstrated significantly reduced association with $A$. castellanii $(1.99 \pm 0.5$ and $2.17 \pm 0.8$ bacteria:amoeba ratio respectively) as compared to $A$. hydrophila $(7 \pm 1.3$ bacteria:amoeba ratio $)(P<0.01$; using paired T-test, one-tail distribution) (Figure $1 \mathrm{~A})$. Here, the term association represents bacteria both inside amoebae and those that were attached on the surface of A. castellanii. A higher recovery of A. hydrophila $(10.36 \% \pm 1.2)$ of the original inoculum was observed as compared to E. aerogenes $(2.44 \% \pm 0.08)$ and $E$. coli $(8 \% \pm 0.9)$ (Figure 1B). Bacteria alone were incubated with various concentrations of SDS, and it was found that $0.5 \%$ SDS had no effect on bacterial viability (data not shown).

Next, to determine the number of intracellular bacteria, invasion/uptake assays were performed. As per association, A. hydrophila exhibited higher invasion/uptake by $A$. castellanii ( $9.94 \pm 0.98$ bacteria:amoeba ratio) compared with $E$. aerogenes $(0.84 \pm 0.002$ bacteria: amoeba ratio $)(P<0.01)$, or $E$. coli $(0.8 \pm 0.05$ bacteria: amoeba ratio) $(P<0.01)$ (Figure $2 \mathrm{~A})$. A higher recovery of $A$. hydrophila $(0.4 \% \pm 0.002)$ of the original inoculum was observed (Figure 2B). Of note, the PBS postgentamicin wash, plated onto nutrient agar plates did not yield any bacterial cfu, confirming that the antibiotic treatment was effective.

\section{E. aerogenes, E. coli and A. hydrophila survived intracellularly of $A$. castellanii}

Assays were performed to determine long term intracellular survival of $A$. hydrophila, E. coli and $E$. aerogenes inside $A$. castellanii. The findings revealed 


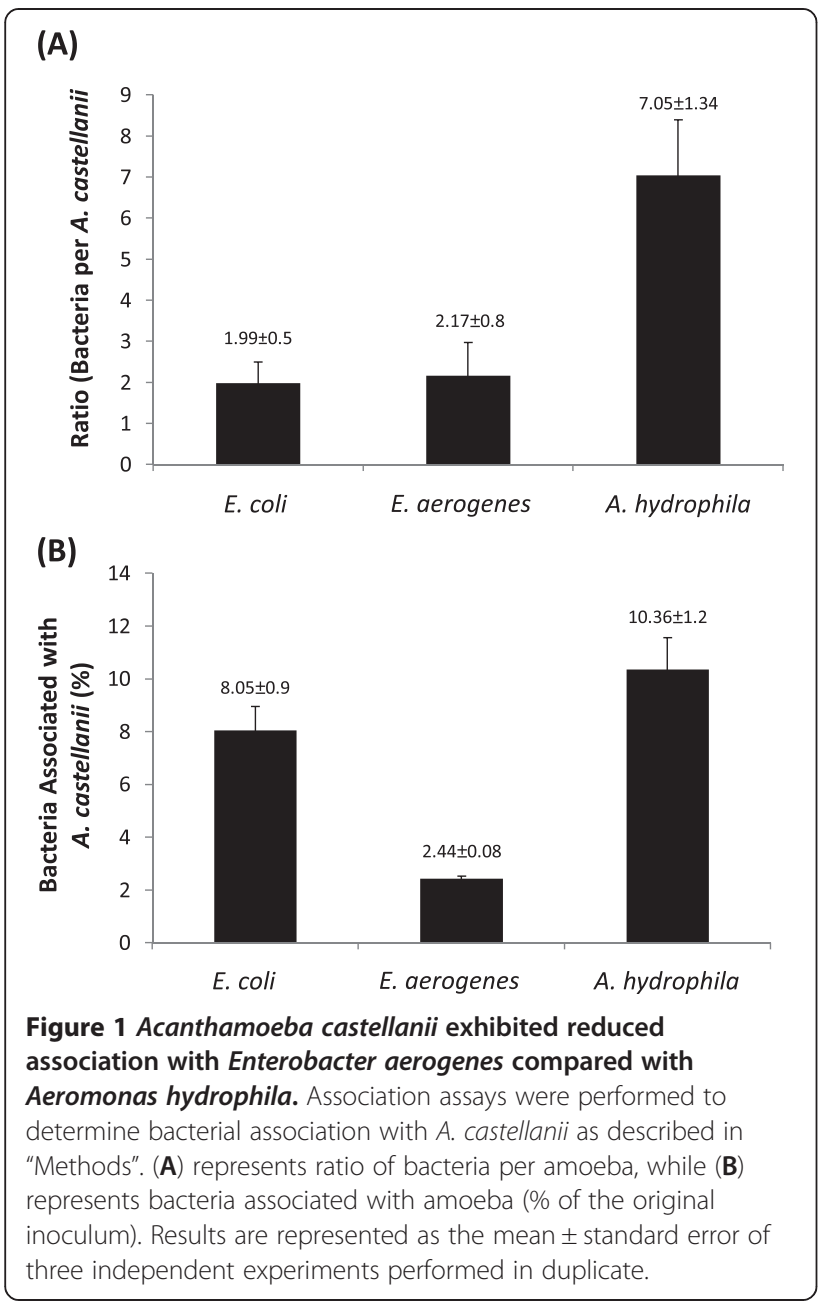

that all three bacterial isolates tested remained viable inside $A$. castellanii, while amoeba remained intact; however $A$. hydrophila exhibited higher survival inside amoebae ( $14.54 \pm 3.3$ bacteria:amoeba ratio), compared with $E$. aerogenes (3.96 \pm 0.7 bacteria:amoeba ratio) $(P<0.05)$, or $E$. coli $(5.85 \pm 1.1$ bacteria:amoeba ratio $)$ $(P<0.05)$ (Figure 3A). A. hydrophila exhibited a higher recovery $(1.13 \% \pm 0.01)$ compared with $E$. aerogenes or E. coli $(P<0.05)$ (Figure 3B).

Intracellular E. aerogenes, E. coli and A. hydrophila survived $A$. castellanii encystment process and were recovered from mature cysts

Viability of E. aerogenes, E. coli and A. hydrophila inside $A$. castellanii during encystment and recovery from mature cysts was determined using intracellular cyst survival assays. The SDS treatment affected cyst viability (no growth observed in PYG) through lysing ostiole membrane leading to recovery of intracellular

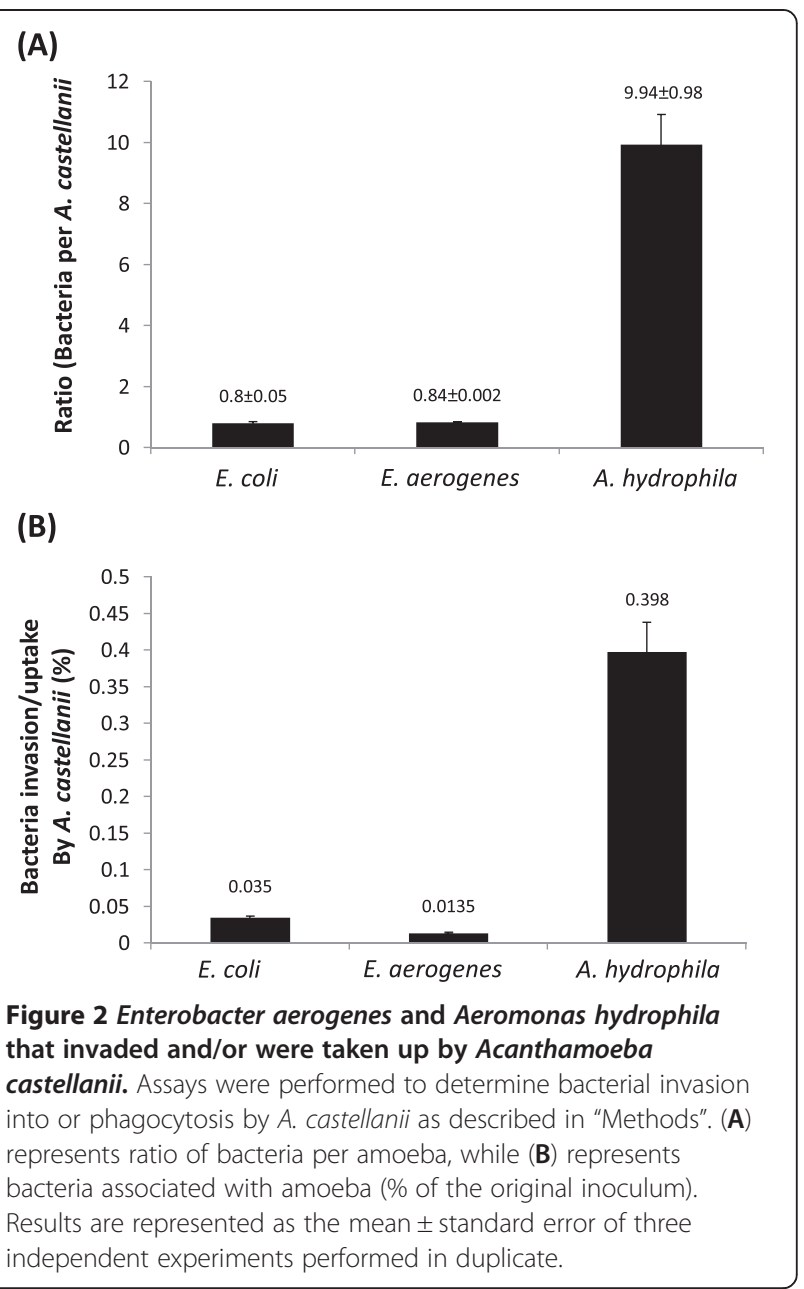

bacteria. The results showed that all three bacterial isolates tested remained viable during encystment (Figure 4). Interestingly, $A$. hydrophila, $E$. coli and $E$. aerogenes exhibited higher levels of recovery from mature cysts (14.13 \pm 0.89 A. hydrophila:amoeba ratio, $10.3 \pm 1.17$ E. aerogenes:amoeba ratio, and $11.95 \pm 0.7$ E. coli:amoeba ratio) (Figure 4). Of the original inoculum, the bacterial recovery was $6.6 \pm 2 \%$ for A. hydrophila, $2.28 \% \pm$ 0.65 for $E$. aerogenes and $3.9 \pm 0.43 \%$ for $E$. coli $(P<0.05)$.

Additionally, co-cultures of $A$. castellanii trophozoites/cysts and E. coli, E. aerogenes and A. hydrophila were stained using Gram staining and observed under a microscope $(\times 400)$. Note that extracellular bacteria are observed in association assays only, suggesting that gentamicin is effective in killing extracellular bacteria in both invasion as well as intracellular survival assays (Figure 5). 


\section{Discussion}

Acanthamoeba serve as a dock for various bacterial pathogens, e.g., Legionella pneumophila (the causative agent of Legionnaires' disease), Coxiella burnetii (Q fever), Pseudomonas aeruginosa (keratitis), Vibrio cholerae (cholera), Helicobacter pylori (gastric ulcers), Listeria monocytogenes (listeriosis), E. coli and Mycobacterium avium (respiratory infections), and may act as a vector to transmit these pathogens to susceptible hosts, but the underlying mechanisms remain incompletely understood [19-21]. Here for the first time, the findings revealed that $A$. hydrophila and $E$. aerogenes associate with and survive inside $A$. castellanii trophozoites and cysts.

Notably, A. hydrophila exhibited higher association, invasion/uptake, and survival inside $A$. castellanii trophozoites compared with $E$. aerogenes. Both $A$. hydrophila and $E$. aerogenes remained viable during the encystment process and multiplied. These findings

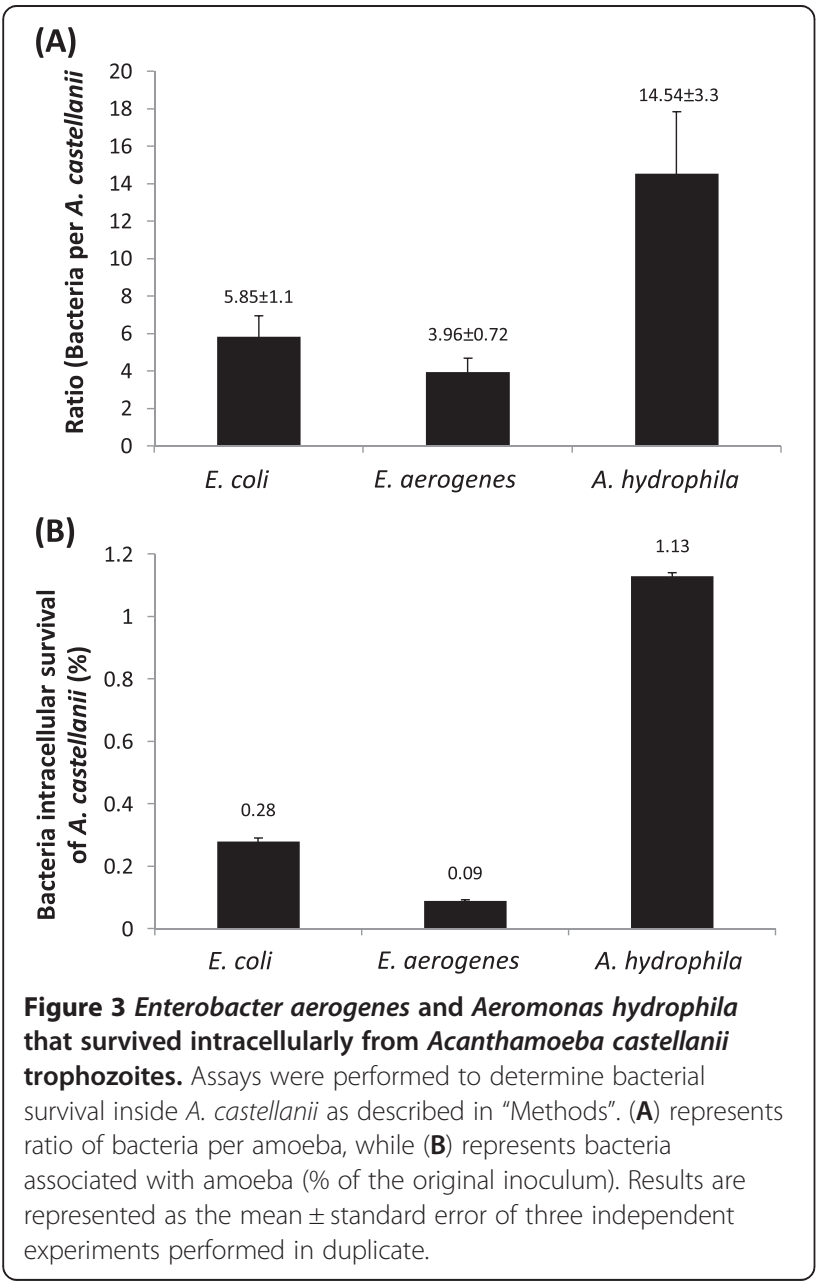

are consistent with previous studies, which showed that A. castellanii promoted the survival and growth of $C$. jejuni [22,23], E. coli K1 [18], and L. pneumophila [24,25]. However, as Acanthamoeba feeds on bacteria by phagocytosis, it is tempting to speculate that amoeba and bacteria are involved in convoluted interactions, the outcome of which is dependent on the virulence of bacteria [26]. For example, the non-invasive bacteria are taken up by Acanthamoeba as a food source, while the invasive bacteria are able to reside and possibly multiply inside amoebae without being killed [18], and use amoebae as (i) a transmission vehicle, (ii) training ground to develop resistance against other phagocytic cells such as human macrophages, and/or enhance virulence through evolution $[27,28]$. This is further strengthened with the fact that Acanthamoeba resemble human macrophages in many ways, particularly in their phagocytic activity and their interactions with various bacterial pathogens $[28,29]$.

Encystment in Acanthamoeba is a complex process that involves morphological changes, termination of cell growth, removal of unnecessary materials, and results in the synthesis of at least two products not detected in trophozoites; cellulose [30] and an acidinsoluble protein-containing material [31]. In simple terms, the trophozoite becomes metabolically inactive (minimal metabolic activity) and encloses itself within a resistant shell. During the encystment process, RNA, proteins, triacylglycerides and glycogen levels are significantly decreased which results in decreased cellular volume and dry weight [32]. Keeping in mind these changes, we determined whether $E$. aerogenes and $A$. hydrophila can remain viable during the encystment process and be recovered from mature cysts or seen as excess materials and be discarded. Our results clearly demonstrated that both A. hydrophila and $E$. aerogenes survived the process of encystment and have the potential to exploit amoebae cysts as biological vectors. Although the molecular mechanisms of (i) precise localization of bacteria within amoebae using TEM, (ii) bacterial survival intracellular of amoebae trophozoites by evading phago-lysosome, (iii) inability of amoeba to dispose of bacteria during encystment, and (iv) how bacteria are retained within mature cysts are unclear, recent studies showed the presence of a diffusible factor produced by amoebae mediating survival and replication of $B$. cepacia and $V$. parahaemolyticus [33,34], which may explain our findings. In conclusion, the present study showed that both A. hydrophila and E. aerogenes exhibited association, invasion/uptake, and intracellular survival of $A$. castellanii, albeit A. hydrophila exhibited higher interactions compared with $E$. 

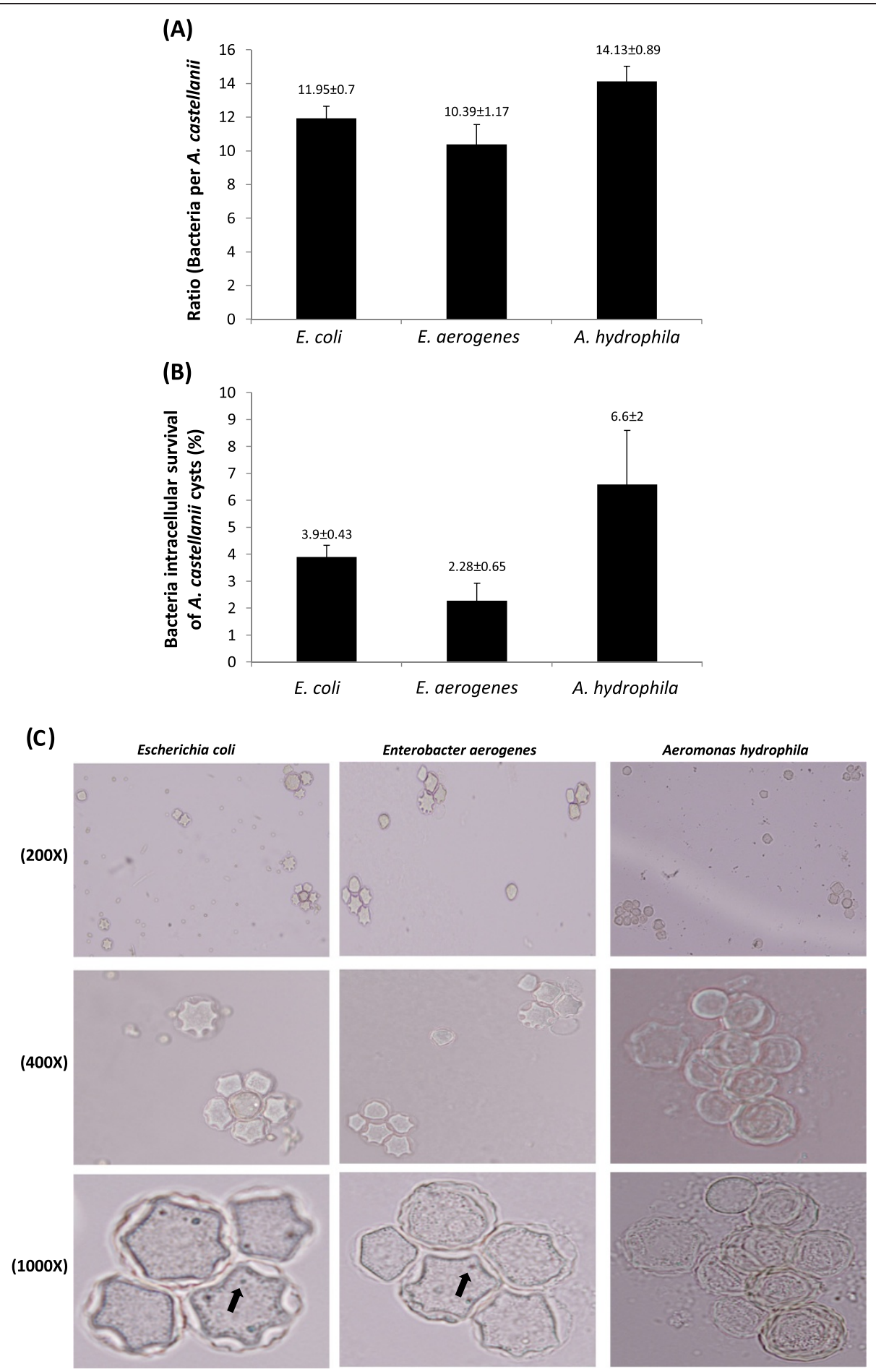

Figure 4 Enterobacter aerogenes and Aeromonas hydrophila encystment process of Acanthamoeba castellanii and recovery from mature cysts. Assays were performed to determine bacterial survival inside A. castellanii during encystment and their recovery from mature cysts as described in "Methods". (A) represents ratio of bacteria per amoeba, while (B) represents bacteria associated with amoeba (\% of the original inoculum). Results are represented as the mean \pm standard error of three independent experiments performed in duplicate. (C) representative micrograph of A. castellanii cysts containing Escehrichia coli K1, Enterobacter aerogenes and Aeromonas hydrophila. Images were taken using light microscopy under different magnifications (200x, 400x, 1000x). Arrows indicate bacteria. 


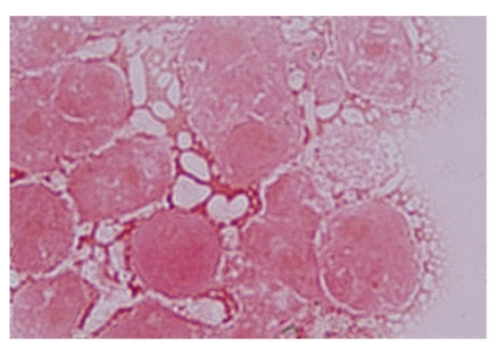

A. castellanii trophozoite alone

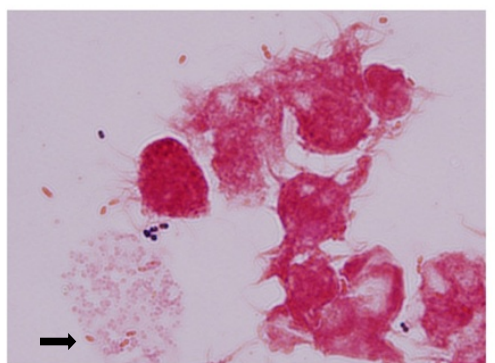

A. castellanii $+A$. hydrophila (association)

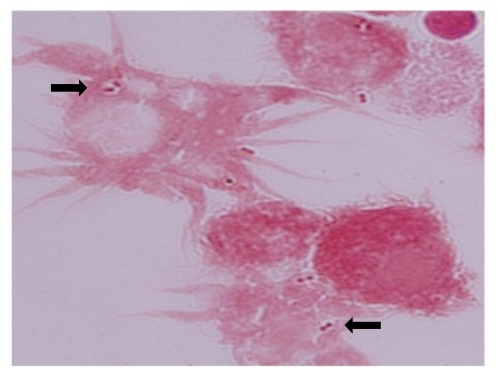

A. castellanii $+A$. hydrophila (invasion)

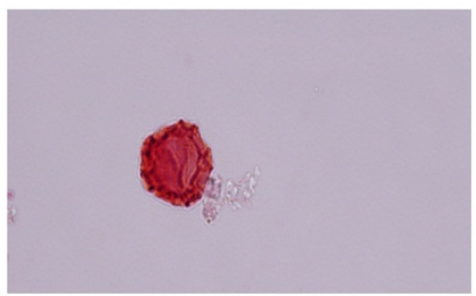

A. castellanii $+A$. hydrophila (encystation)

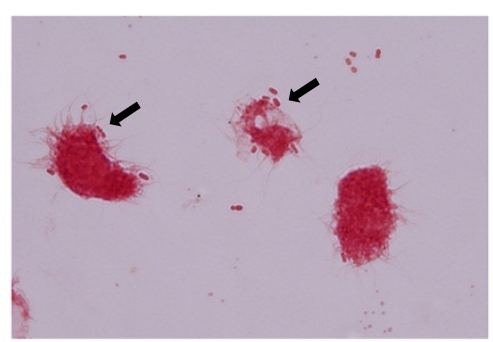

A. castellanii + E. aerogenes (association)

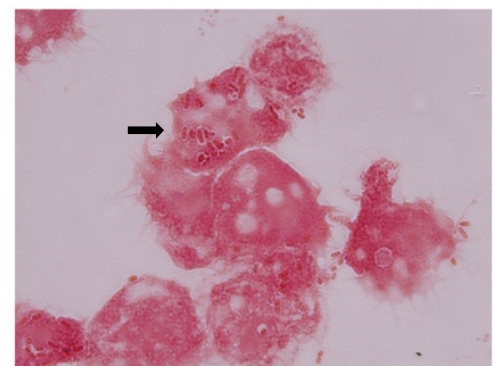

A. castellanii + E. aerogenes (invasion)

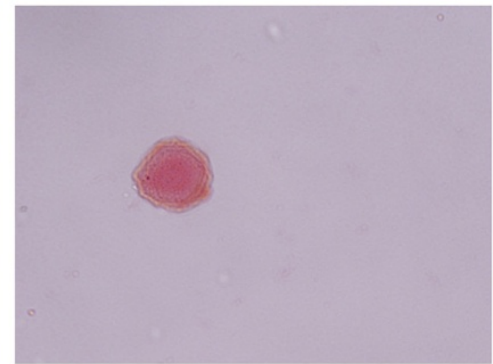

A. castellanii cyst alone

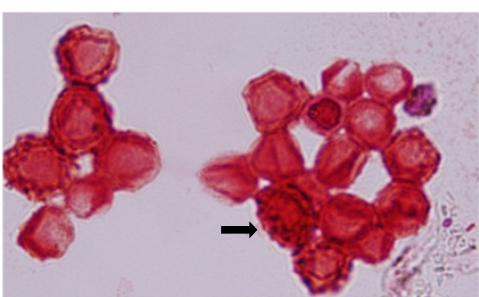

A. castellanii + E. aerogenes (encystation)

Figure 5 Representative micrograph of Acanthamoeba castellanii interactions with Escehrichia coli K1, Enterobacter aerogenes and Aeromonas hydrophila. Assays were performed to determine bacterial association with and invasion of A. castellanii, as well as bacterial survival inside A. castellanii cysts as described in "Methods". Finally, samples were stained using Gram staining and observed under a microscope ( $\times 400)$. Note that extracellular bacteria are observed in association assays only, suggesting that gentamicin is effective in killing extracellular bacteria in both invasion as well as intracellular survival assays. Arrows indicate bacteria.

aerogenes. Therefore, A. hydrophila and E. aerogenes also joined the ranks of other bacteria that could benefit from A. castellanii.

\section{Conclusions}

For the first time, it is shown that A. hydrophila and $E$. aerogenes associate with and survive intracellular of $A$. castellanii trophozoites and cysts. Thus, $A$. hydrophila and $E$. aerogenes also joined the ranks of other bacteria that could benefit from A. castellanii.
Because cysts can be airborne, these findings suggest that Acanthamoeba is a potential vector in the transmission of A. hydrophila and E. aerogenes to susceptible hosts.

\section{Competing interests}

The authors declare that they have no competing interests.

\section{Authors' contributions}

NAK conceived the study. FAY and RS designed and conducted all experiments under the supervision of NAK. FAY, RS, and NAK contributed to the writing of the manuscript. All authors approved the final manuscript. 


\section{Acknowledgements}

We are thankful to IDRL group at the Aga Khan University for performing antibiotic susceptibility tests. This work was supported by The Aga Khan University.

Received: 27 March 2013 Accepted: 27 May 2013

Published: 7 June 2013

\section{References}

1. Castellani A: An amoeba found in culture of yeast: preliminary note. J Trop Med Hyg 1930, 33:160.

2. Douglas M: Notes on the classification of the amoeba found by Castellani on culture of a yeast-like fungus. J Trop Med Hyg 1930, 33:258-59.

3. Volkonsky M: Hartmanella castellanii Douglas, et classification des hartmannelles. Arch Zool Exp Gen 1931, 72:317-39.

4. Greub G, Raoult D: Microorganisms resistant to free-living amoebae. Clin Microbiol Rev 2004, 17:413-33.

5. Gallo S, Chevalier J, Mahamoud A, Eyraud A, Pagès JM, Barbe J: 4-alkoxy and 4-thioalkoxyquinoline derivatives as chemosensitizers for the chloramphenicol-resistant clinical Enterobacter aerogenes 27 strain. Int J Antimicrob Agents 2003, 22:270-73.

6. Arpin C, Coze C, Rogues AM, Gachie JP, Bebear C, Quentin C: Epidemiological study of an outbreak due to multidrug-resistant Enterobacter aerogenes in a medical intensive care unit. J Clin Microbiol 1996, 34:2163-9.

7. De Champs C, Henquell C, Guelon D, Sirot D, Gazuy N, Sirot J: Clinical and bacteriological study of nosocomial infections due to Enterobacter aerogenes resistant to imipenem. J Clin Microbiol 1993, 31:123-27.

8. De Gheldre Y, Maes N, Rost F, De Ryck R, Clevenbergh P, Vincent JL, Struelens MJ: Molecular epidemiology of an outbreak of multidrugresistant Enterobacter aerogenes infections and in vivo emergence of imipenem resistance. J Clin Microbiol 1997, 35:152-60.

9. Georghiou PR, Hamill RJ, Wright CE, Versalovic J, Koeuth T, Watson DA Lupski JR: Molecular epidemiology of infections due to Enterobacteraerogenes: identification of hospital outbreak-associated strains by molecular techniques. Clin Infect Dis 1995, 20:84-4.

10. Meyers HB, Fontanilla E, Mascola L: Risk factors for development of sepsis in an hospital outbreak of Enterobacter aerogenes. Am J Infect Control 1988, 16:118-22

11. Ashraf T, Abulhamd: Characterization of Aeromonas hydrophila Isolated from Aquatic environments Using Phenotypic and Genotyping Methods. Res J Agri Biol Sci 2009, 5:923-93.

12. Handfield $M$, Simard $P$, Letarte R: Differential media for quantitative recovery of waterborne Aeromonashydrophila. Appl Environ Microbiol 1996, 62:3544-7.

13. Sissons J, Kim KS, Stins M, Jayasekera S, Alsam S, Khan NA: Acanthamoeba castellanii induces host cell death via a phosphatidylinositol 3-kinase -dependent mechanism. Infect Immun 2005, 73:2704-8.

14. Khan NA, Kim Y, Shin S, Kim KS: FimH-mediated Escherichia coli K1 invasion of human brain microvascular endothelial cells. Cell Microbio 2007, 9(1):169-78.

15. Khan NA, Wang Y, Kim KJ, Woong J, Wass CA, Kim KS: Role of cytotoxic necrotizing factor-1 in Escherichia coli K1 invasion into the central nervous system. J Biol Chem 2002, 277(18):15607-12.

16. Ho PL, Chow KH, Yuen KY, Ng WS, Chau PY: Comparison of a novel, inhibitor-potentiated disc-diffusion test with other methodsfor the detection of extended-spectrum beta-lactamases in Escherichia coli and Klebsiella pneumoniae. J Antimicrob Chemother 1998, 42:49-4.

17. National Committee for Clinical Laboratory Standards: Performance Standards for antimicrobial susceptibility testing. In NCCLS approved standard M100-S14. Wayne, PA USA: NCCLS; 2004

18. Alsam S, Jeong SR, Sissons J, Dudley R, Kim KS, Khan NA: Escherichia coli interactions with Acanthamoeba: a symbiosis with environmental and clinical implications. Med Microbiol 2006, 55:689-94.

19. Khan NA: Acanthamoeba: Biology and Pathogenesis. Caister Academic Press; 2009:43-1. ISBN 978-1-904455.

20. Bui XT, Winding A, Qvortrup K, Wolff A, Bang DD, Creuzenet C: Survival of Campylobacter jejuni in co-culture with Acanthamoeba castellanii: role of amoeba-mediated depletion of dissolved oxygen. Environ Microbiol 2012, 14:2034-7.
21. Siddiqui R, Khan NA: Biology and Pathogenesis of Acanthamoeba. Parasit Vectors 2012, 5:6.

22. Axelsson-Olsson D, Waldenstrom J, Broman T, Olsen B, Holmberg M: Protozoan Acanthamoeba polyphaga as a potential reservoir for Campylobacterjejuni. Appl Environ Microbiol 2005, 71:987-92.

23. Axelsson-Olsson D, Olofsson J, Svensson L, Griekspoor P, Waldenström J, Ellström P, Olsen B: Amoebae and algae can prolong the survival of Campylobacter species in co-culture. Exp Parasitol 2010, 126:59-4.

24. Fields BS: The molecular ecology of legionellae. Trends Microbiol 1996, 4:286-90.

25. Kilvington S, Price J: Survival of Legionella pneumophila within cysts of Acanthamoeba polyphaga following chlorine exposure. J Appl Bacteriol 1990, 68:519-25.

26. Siddiqui R, Malik H, Sagheer M, Jung SY, Khan NA: The type III secretion system is involved in Escherichia coli K1 interactions with Acanthamoeba. Exp Parasitol 2011, 128:409-13.

27. Salah IB, Ghigo E, Drancourt M: Free-living amoebae, a training field for macrophage resistance of mycobacteria. Clin Microbiol Infect 2009, 15:894-05.

28. Siddiqui $R$, Khan NA: War of the microbial worlds: who is the beneficiary in Acanthamoeba-bacterial interactions? Exp Parasitol 2012, 130:311-13.

29. Yan L, Cerny RL, Cirillo JD: Evidence that hsp90 is involved in the altered interactions of Acanthamoeba castellanii variants with bacteria. Eukaryot Cell 2004, 3:567-78.

30. Tomlinson $\mathrm{G}$, Jones EA: Isolation of cellulose from then cyst wall of a soil amoeba. Biochim Biophys Acta 1962, 63:194-200.

31. Neff RJ, Neff RH: The biochemistry of amoebic encystment. Symp Soc Exp Biol 1969, 23:51-81.

32. Weisman RA: Differentiation in Acanthamoeba castellanii. Annu Rev Microbiol 1976, 30:189-19.

33. Marolda CL, Hauröder $B$, John MA, Michel R, Valvano MA: Intracellular survival and saprophytic growth of isolates from the Burkholderiacepacia complex in free-living amoebae. Microbiol 1999, 145:1509-7.

34. Laskowski-Arce MA, Orth K: Acanthamoeba castellanii promotes the survival of Vibrio parahaemolyticus. Appl Environ Microbiol 2008, 74:7183-8.

doi:10.1186/1756-3305-6-169

Cite this article as: Yousuf et al.: Acanthamoeba castellanii of the T4 genotype is

a potential environmental host for Enterobacter aerogenes and Aeromonas hydrophila. Parasites \& Vectors 2013 6:169.

\section{Submit your next manuscript to BioMed Central and take full advantage of:}

- Convenient online submission

- Thorough peer review

- No space constraints or color figure charges

- Immediate publication on acceptance

- Inclusion in PubMed, CAS, Scopus and Google Scholar

- Research which is freely available for redistribution 